\title{
USING RESPONSE CARDS TO INCREASE STUDENT PARTICIPATION IN AN ELEMENTARY CLASSROOM
}

\author{
Janani S. Narayan, Winuam L. Heward, and Ralph Gardner, III \\ THE OHIO STATE UNIVERSITY
}

Frances H. Courson

COLLEGE OF CHARLESTON

AND

Christine K. Omness

COLUMBUS PUBLIC SCHOOLS

\begin{abstract}
The use of response cards during large-group social studies instruction was evaluated in a fourthgrade classroom. The experiment consisted of two conditions, hand raising and write-on response cards, alternated in an ABAB design. During baseline, the teacher called upon 1 student who had raised his or her hand in response to the teacher's question. During the response-card condition, each student in the class was provided with a white laminated board on which to write one- or two-word answers in response to each question asked by the teacher. Rate of active student response during instruction was much higher with response cards than with hand raising. Most students scored higher on daily quizzes following sessions in which response cards were used than they did on quizzes that followed hand-raising sessions. Response cards were preferred over hand raising by 19 of the 20 students in the class.
\end{abstract}

DESCRIPTORS: academic behavior, response cards, students

A consistent finding of recent educational research is that student academic achievement is correlated with active student responding in the classroom. Although investigators who use the methods of group comparison or statistical inference refer to this critical variable as academic learning time (e.g., Fisher \& Berliner, 1985) and repeated measures or single subject analysts are more likely to use the term opportunity to respond (e.g., Greenwood, Delquadri, \& Hall, 1984), the findings from both camps are essentially the same. As John Dewey (1916) said more than 70 years ago, "Students learn by doing."

Unfortunately, observational studies have found

This report is based on a thesis submitted by the first author in partial fulfillment of the requirements for the Master of Arts degree at The Ohio State University. The research was supported in part by a Leadership Training Grant (G008715568-88) from the Office of Special Education and Rehabilitation Services, U.S. Department of Education.

Correspondence concerning this study may be addressed to William L. Heward, Applied Behavior Analysis Program, The Ohio State University, 356 Arps Hall, 1945 N. High St., Columbus, Ohio 43210. distressingly low levels of active student engagement in the classroom. For example, Hall, Delquadri, Greenwood, and Thurston (1982) reported that although teachers in six inner-city elementary classrooms allocated $75 \%$ of the school day for academic instruction, their students spent less than $1 \%$ of the day responding in each of the following ways: reading aloud, answering questions, asking questions, and reciting. Students spent the largest portion of each school day, as much as $45 \%$ of the available instructional time, passively attending to the teacher.

Various strategies for increasing the frequency of active student response, and in turn improving academic achievement, have been successfully demonstrated. These strategies include classwide peer tutoring systems (Cooke, Heron, \& Heward, 1983; Delquadri, Greenwood, Whorton, Carta, \& Hall, 1986), computer-assisted instruction (Balajthy, 1984; Stallard, 1982), and self-directed learning (Kosiewicz, Hallahan, Lloyd, \& Graves, 1982; Lovitt, 1984). However, none of these approaches is easily applicable to teacher-directed large-group 
instruction. Active student involvement, when it does occur during teacher-led whole-class instruction, is often characterized by the teacher calling upon 1 student at a time to respond. Although this traditional method of having students raise their hands provides an opportunity for active response by the student who is called upon, all other students in the classroom are relegated to passive participation.

There is a need to develop tactics for providing every student in the class with many opportunities to respond during teacher-led classwide instruction. Ideally, such methods for increasing active student response should be relatively low in cost (both in dollars and in teacher time), be easy to implement, be enjoyable for both students and teachers, be adaptable to various content areas, and produce better learning outcomes than the instructional procedures they are to replace. Three methods that meet these requirements are choral responding (Heward, Courson, \& Narayan, 1989; Sindelar, Bursuck, \& Halle, 1986), timed trials (Van Houten, Morrison, Jarvis, \& McDonald, 1974; Van Houten \& Thompson, 1976), and guided lecture notes (Kline, 1986; Lovitt, Rudsit, Jenkins, Pious, \& Benedetti, 1985; Yang, 1988). Another method that may also provide these benefits is the use of student response cards. A response card is any item that can be held up simultaneously by every student in the class as a means of responding to a question or problem presented by the teacher. This study evaluated the use of response cards in a fourthgrade social studies class.

\section{METHOD}

\section{Subjects and Setting}

The research was conducted in a regular fourthgrade classroom in an urban public elementary school. All 20 children in the class -8 boys and 12 girls ranging in age from 9 to 11 years-participated in the study. The classroom teacher identified 6 students who, in her judgment, represented the range of overall skills levels in the class. Re- sponses of these 6 students during instruction were observed and recorded throughout the study.

The classroom was equipped with an overhead projector and screen. Students' desks and chairs were arranged in standard rows and columns, providing each student with an unobstructed view of the screen. The first author served as teacher during the study. The students' regular teacher served as the primary observer during the instructional sessions. She sat in the front of the room and had a clear view of the 6 target students. The 6 target students were divided into two equal groups, and each group was observed on alternating response opportunities. The students in each group sat close to one another, enabling the observer to record the occurrence and accuracy of all 3 students' responses on the same trial.

\section{Dependent Variables}

Four dependent variables were measured: (a) teacher presentation rate, (b) number of student responses, (c) accuracy of student responses, and (d) daily quiz scores.

Teacher presentation rate. The rate at which the teacher presented response opportunities to students was measured in all sessions. A response opportunity consisted of three parts: the teacher's presentation of a question, student response to the question, and the teacher's delivery of feedback to the student(s).

Number of student responses. During handraising sessions, a student response was counted whenever a target student raised his or her hand at least head high and answered orally when called upon by the teacher. (During hand-raising sessions, data were also recorded on each target student's rate of hand raising, whether or not he or she was called on to answer the question.) During responsecard sessions, a student response was counted whenever a target student wrote his or her answer on a response card to the teacher's cue, "Write your answer," and then held up the card in response to the teacher's cue, "Hold up your card."

The observer timed each session with a stop watch, stopping the watch for interruptions (e.g., 
a message from the principal over the public address system) and starting the watch again when instruction resumed. Starting and stopping of the stopwatch was cued by the teacher.

Accuracy of student responses. A correct response was recorded whenever a target student responded, either orally or with a response card depending upon the experimental condition, with the appropriate answer. The observer had a list of all acceptable answers attached to her copy of each session's lecture notes. An accuracy percentage for each of the 6 target students was calculated by dividing the number of correct responses by the total number of responses emitted.

Daily quiz scores. Immediately following each instructional session, a 10-question quiz was administered over the social studies content just presented. Each quiz consisted of five recognition questions (multiple choice) and five recall questions requiring a one- or two-word answer. Quizzes were scored using a prepared answer key.

\section{Reliability of Data}

A second observer independently recorded the responses of the 6 target students during two sessions in each of the four experimental phases. The two observers sat $3 \mathrm{~m}$ apart in the front corner of the room to the teacher's right. The primary observer used her hand to signal the second observer on even-numbered trials to ensure that they were both observing the same group of 3 target students on each response opportunity. Interobserver agreement for all dependent variables was calculated on an interval-by-interval basis. During the two handraising phases, interobserver agreement for response attempts (i.e., hand raises) ranged across students from $83.3 \%$ to $100 \%$. Agreement for both total responses and correct responses during hand raising ranged from $98.6 \%$ to $100 \%$. During responsecard instruction, interobserver agreement for total responses ranged from $92.9 \%$ to $100 \%$, and agreement for correct responses ranged from $82.8 \%$ to $100 \%$.

The second observer also independently scored unmarked photocopies of $25 \%$ of all daily quizzes. Mean interobserver agreement for the daily quizzes, which was also calculated on an item-by-item basis, ranged across students from $95 \%$ to $100 \%$, with an overall mean of $97.8 \%$.

\section{Experimental Design}

All subjects were exposed via an $\mathrm{ABAB}$ reversal design to both experimental conditions, hand raising (A) and response cards (B).

\section{Procedure}

General procedure. Each session consisted of 20 min of instruction followed by the quiz. During approximately the first $10 \mathrm{~min}$, the teacher presented information with the overhead projector and orally questioned the students after each fact or concept had been presented. During the remainder of the instructional time, the teacher asked a series of questions reviewing all of the facts or concepts she had just presented. Students responded to all teacher-posed questions using the response mode (i.e., hand raising or response cards) in operation during that session. The third and final part of each session was the administration of the daily quiz. Students' quiz scores counted toward their social studies grades. To control for the wide range of reading levels in the class, the teacher sequentially projected each quiz question on the overhead projector while reading each question aloud twice.

$H$ and raising. Two days prior to Session 1, the teacher held a hand-raising training session for about $20 \mathrm{~min}$. Using a science lesson, the teacher trained the students on the correct procedure for raising their hands and responding to her questions. Both observers were present and practiced recording the responses of the target students.

During the hand-raising condition, the teacher waited $3 \mathrm{~s}$ after asking a question before calling upon an individual student whose hand was raised. A list of randomly ordered student names was used to determine which student should be called upon after each question. The selection of students was further randomized by the fact that each student did not raise his or her hand to every question. If the student who was to be called upon did not raise his or her hand, the teacher went to the next 
name on the list, until she came to a student whose hand was raised.

The teacher gave verbal praise for correct answers (e.g., " 'Great (student's name)! Austin is the capital of Texas.") and corrective feedback for incorrect answers (e.g., "No, the answer is Austin. Austin is the capital of Texas."). Feedback statements were controlled so that all students always heard the correct answer twice.

Response cards. Teacher presentation and question-asking procedures during the response-card condition were identical to those employed during the hand-raising condition. Each student was provided with a white laminated particleboard $(9$ in. by 12 in., $22.9 \mathrm{~cm}$ by $30.5 \mathrm{~cm}$ ) on which to write his or her responses to the teacher's questions with a dry erase marker. Immediately prior to the first response-card session, the teacher conducted a 10min response-card training session using a science lesson. Students were taught to respond to the teacher's questions by printing their answers in one or two words on their response cards. After posing a question the teacher said, "write," to cue the students to begin writing. After counting to herself for $5 \mathrm{~s}$, the teacher instructed the students to hold their cards above their heads so she could see all students' responses by saying, "Hold up your cards." After quickly scanning all the students' responses, the teacher provided feedback. She then said, "Put down your cards and erase your answers." The students did so and were then ready for the next question.

Teacher praise and feedback were given after each student response. If everyone in the class had the right answer the teacher addressed the feedback to the whole class (e.g., "Good, class, the states from Maine to Connecticut are sometimes called New England."'). If some of the students' responses were incorrect, the teacher said, for example, "I see many of you have New England as the answer. That is correct. New England is the name used to refer to the states from Maine to Connecticut." If no student had the correct response, the teacher said, for example, "I see no one has the right answer. The right answer is New England. New England is the name often used to refer to the states from Maine to Connecticut." As during the handraising condition, this feedback procedure controlled the number of times (twice) students wrote and/or heard the correct answer to each question during instruction.

Some problems occurred during the first two sessions in which the response cards were used because many of the students were doodling on their response cards and thereby missed some of the teacher's questions. At the beginning of the third response-card session, the teacher told the students that, contingent upon their writing only answers to the teacher's questions on their cards during instruction, $2 \mathrm{~min}$ of free time would be provided at the end of each day's session so that they could draw on the response cards. Thereafter, there were no more problems with students playing with or drawing on their response cards during the lesson.

\section{RESULTS}

\section{Teacher Presentation Rate}

Mean teacher presentation rate for the two handraising phases combined was 1.9 response opportunities per minute. During the two phases in which response cards were used, the teacher presented response opportunities at an average rate of 1.2 per minute.

\section{Student Responding During Instruction}

Figure 1 shows the number of responses emitted by the 6 target students during each session of the study. Also shown is the number of times each student raised his or her hand during the two handraising phases. During the hand-raising sessions, the average number of times a target student raised his or her hand was 11.6 , with a range of 9.2 to 13.7. The number of responses (i.e., orally answering the teacher's question) for the target students averaged 0.9 per session, with a range of 0.69 to 1.57 responses per session. The target students emitted an average of 0.74 correct responses per session during the hand-raising condition, ranging from 0.69 to 1.36 .

When response cards were used, the target stu- 

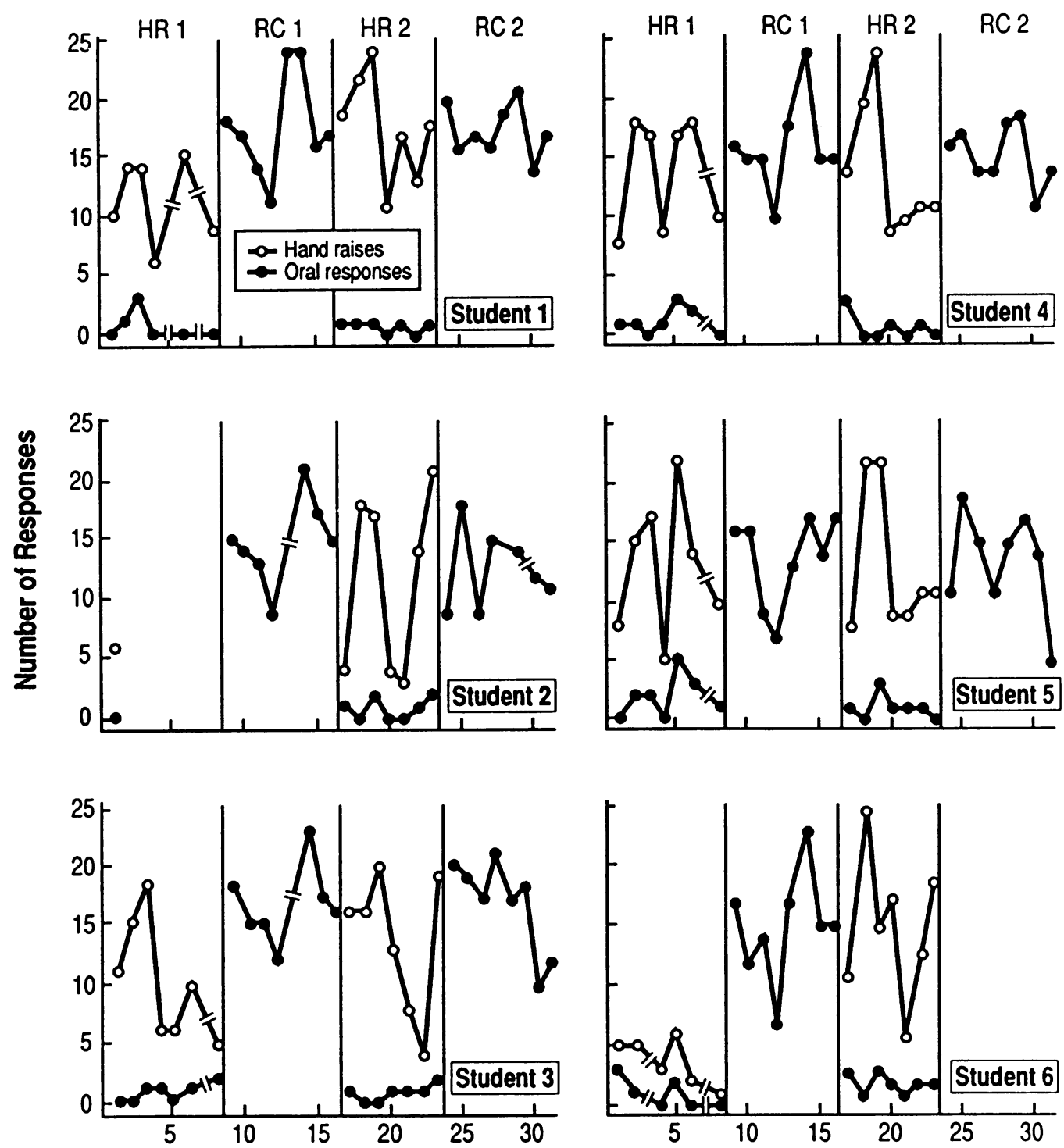

\section{Sessions}

Figure 1. Number of responses and hand raises by Students 1-6 during hand-raising (HR) and response-card (RC) conditions. Breaks in data paths indicate student absences.

dents actively responded to teacher questions an average of 15.6 times per session, with a range of 13.5 to 17.6 responses per session. The 6 observed students averaged 13.0 correct responses each session with response cards, with a range of 8.9 to 15.4 .

Table 1 summarizes the total number of academic responses emitted by each target student during the hand-raising and response-card condi- tions. Accuracy of student response during instruction was similar in both conditions.

\section{Daily Quiz Scores}

Table 2 shows the mean daily quiz score (i.e., number of correct answers out of 10) obtained by each student during each phase of the experiment. Overall, 13 students earned better quiz scores during the first response-card phase than they earned 
Table 1

Total Number of Student Responses, Response Opportunities, Participation as a Percentage of Response Opportunities Answered, and Percentage Accuracy of Student Responses During Both Experimental Conditions

\begin{tabular}{|c|c|c|c|c|c|c|c|c|}
\hline \multirow[b]{2}{*}{ Students } & \multicolumn{4}{|c|}{ Hand raising (15) } & \multicolumn{4}{|c|}{ Response cards (16) } \\
\hline & $\begin{array}{c}\text { Re- } \\
\text { sponses }\end{array}$ & $\begin{array}{l}\text { Response } \\
\text { oppor- } \\
\text { tunities }^{b}\end{array}$ & $\begin{array}{l}\text { Partici- } \\
\text { pation }\end{array}$ & Accuracy & $\begin{array}{c}\text { Re- } \\
\text { sponses }\end{array}$ & $\begin{array}{c}\text { Response } \\
\text { Oppor- } \\
\text { tunities }\end{array}$ & $\begin{array}{l}\text { Partici- } \\
\text { pation }\end{array}$ & Accuracy \\
\hline 1 & 9 & 329 & 2.7 & 100.0 & 281 & 304 & 92.4 & 87.9 \\
\hline 2 & 11 & 179 & 3.4 & 83.3 & 208 & 261 & 72.1 & 79.7 \\
\hline 3 & 11 & 359 & 3.1 & 81.8 & 250 & 280 & 89.3 & 88.0 \\
\hline 4 & 13 & 359 & 3.6 & 92.3 & 251 & 304 & 82.6 & 93.6 \\
\hline 5 & 20 & 359 & 5.6 & 55.0 & 216 & 304 & 71.0 & 66.2 \\
\hline 6 & 20 & 338 & 5.9 & 95.0 & 120 & 149 & 80.5 & 90.0 \\
\hline Total & 79 & 1,923 & 4.1 & 82.2 & 1,326 & 1,602 & 82.8 & 83.2 \\
\hline
\end{tabular}

- Numbers in parentheses indicate number of sessions in each condition.

b Differences in response opportunities across students are a function of absences.

during the first hand-raising phase, and the mean quiz score for 19 of the 20 students was higher during the final response-card phase than it was during the previous hand-raising phase.

Table 2

Mean Daily Quiz Score for Each Student During HandRaising (HR) and Response-Card (RC) Phases. Maximum Score is 10 .

\begin{tabular}{ccccc}
\hline Students & HR 1 & RC 1 & HR 2 & RC 2 \\
\hline $1^{2}$ & 7.7 & 9.0 & $\mathbf{8 . 0}$ & $\mathbf{8 . 4}$ \\
2 & 8.5 & 7.1 & 6.0 & 6.5 \\
3 & $\mathbf{8 . 4}$ & 6.7 & 9.0 \\
4 & 9.0 & $\mathbf{8 . 3}$ & $\mathbf{8 . 1}$ & $\mathbf{8 . 6}$ \\
5 & 4.8 & 4.4 & 4.6 & 4.9 \\
6 & 7.8 & $\mathbf{8 . 9}$ & 7.1 & 7.9 \\
7 & 6.6 & $\mathbf{8 . 1}$ & 5.6 & 7.5 \\
8 & 6.1 & 9.0 & 6.7 & 6.8 \\
9 & 7.4 & $\mathbf{8 . 6}$ & 7.6 & 7.0 \\
10 & 5.4 & 6.6 & 5.0 & 7.8 \\
11 & $\mathbf{8 . 3}$ & $\mathbf{8 . 9}$ & 7.5 & 7.9 \\
12 & $\mathbf{8 . 4}$ & $\mathbf{8 . 8}$ & $\mathbf{8 . 0}$ & 9.0 \\
13 & 7.2 & 6.8 & 5.1 & 6.5 \\
14 & 6.7 & $\mathbf{8 . 6}$ & 6.4 & 7.6 \\
15 & $\mathbf{8 . 1}$ & $\mathbf{8 . 2}$ & 7.0 & $\mathbf{8 . 5}$ \\
16 & 7.9 & $\mathbf{8 . 5}$ & 6.6 & $\mathbf{8 . 2}$ \\
17 & 5.1 & - & 5.0 & $\mathbf{8 . 0}$ \\
18 & $\mathbf{8 . 6}$ & 9.8 & 7.5 & 9.0 \\
19 & $\mathbf{8 . 5}$ & $\mathbf{8 . 5}$ & 6.1 & $\mathbf{8 . 2}$ \\
20 & 7.2 & $\mathbf{8 . 9}$ & 5.6 & $\mathbf{8 . 1}$ \\
Group M & 7.3 & $\mathbf{8 . 2}$ & 6.5 & 7.8 \\
\hline
\end{tabular}

- Students 1-6 were observed during instruction.

${ }^{b}$ Dash indicates three or fewer quiz scores per phase.

\section{Students' Preferences and Opinions}

When asked which method of instruction they preferred (via individual interviews at the conclusion of the study), 19 of the 20 students chose response cards over hand raising. When asked which response mode they felt helped them learn better, 12 students chose response cards and 8 selected hand raising. In answering the question of which response mode produced better quiz scores for them, 14 students selected response cards and 6 checked hand raising. Four of the 6 students who indicated they believed hand raising helped them earn better quiz scores actually scored higher on daily quizzes following instruction with response cards.

\section{DISCUSSION}

Response cards proved superior to hand raising in providing students with more frequent opportunities to respond actively during classwide social studies instruction. Although teacher presentation rate was higher with the hand-raising procedure than it was with response cards, this was most likely due to the 5-s wait time provided for students to write their answers compared to the shorter 3-s wait time used with hand raising (to make the handraising procedure as efficient as possible) and allowing students a few seconds to erase their response cards before asking the next question. 
However, because only 1 student at a time could orally answer each question during hand-raising instruction, a total of only about 40 active learning trials occurred during each session (1.9 presentations $\times 1$ student $\times 20 \mathrm{~min}$ ). When response cards were used, an average of 480 response opportunities were presented each session (1.2 presentations $\times 20$ students $\times 20 \mathrm{~min})$. The participation level of $83 \%$ during the response-card conditions means that an average of 398 active learning trials occurred during every $20 \mathrm{~min}$ of instruction in which response cards were used.

Using the behavior of the 6 target students (each of whom was observed on only every other trial) as an estimate for the entire class, each student answered slightly less than two questions in a typical 20-min session when hand raising was the response mode. With response cards, each student's opportunity to respond actively to the content of the lesson increased to an average of approximately 30 responses per session. The cumulative effect of using response cards for just $20 \mathrm{~min}$ per day over an entire school year (180 days) would provide each student in the class with more than 5,000 additional opportunities to respond.

Accuracy of student responses during instruction was not impaired by the high participation rate with response cards compared to hand raising to answer a teacher-posed question. These results are somewhat surprising because it could be argued that the hand-raising procedure entails a built-in bias for higher response accuracy. Students are more likely to raise their hands for questions that they believe they can answer, whereas with response cards, students are expected to give an answer to every question. Of course, it was impossible to measure the frequency with which students may have covertly responded to questions during the hand-raising condition.

Because only 1 student at a time actively responds during a traditional hand-raising procedure, the teacher has no objective information about the ability of other students to respond correctly to the question or problem being presented. However, when each student in the class holds up a response card, the teacher can see and evaluate each student's response. The teacher had no difficulty in quickly scanning the held-up cards of 20 students. Although there is no doubt a limit to the size of the class in which response cards could be used effectively, it is likely that response cards could be used with somewhat larger classes as well.

Although data were not taken on students' ontask behavior, anecdotal reports by the teacher and the observers indicated that, during hand-raising instruction, it was common for as many as 5 or 6 students to put their heads on their desks and quit paying attention to the lesson. In almost every instance, students who dropped out had begun the lesson by raising their hands in the attempt to answer questions. In the postresearch interview, some of these students stated that after several trials of not being called upon by the teacher they became "frustrated and gave up."

The fact that scores on daily quizzes improved for most students when their opportunities to respond increased lends further support to the growing body of research showing a relationship between active student response and academic achievement (Greenwood et al., 1984). In addition, this study serves as a demonstration of a low-cost method for substantially increasing the frequency of active response during whole-class instruction. One possible reason for the low rates of active student responding found in many classrooms is that increasing students' opportunities to respond with most traditional methods (e.g., requiring students to complete more workbook pages) is too costly in terms of teacher time (e.g., more workbook pages for the teacher to evaluate) (Hall et al., 1982). Using response cards, however, entails little preparation before the lesson (preparation of the questions or problems to be presented may be necessary in some subject areas to ensure a lively presentation pace) and requires no teacher time following the activity.

Although choral responding is also an effective low-cost tactic for getting each student in the group to participate actively (Heward et al., 1989), a greatly reduced noise level and the ability to discern each student's answer are two advantages of response cards over choral responding. Response cards are inexpensive and can be used in virtually any 
subject area. A building supply store cut 40 of the response cards from one sheet of laminated particleboard ( $4 \mathrm{ft}$ by $8 \mathrm{ft}$ ) at a total cost of $\$ 15$. Finally, students appear to enjoy using response cards.

Although the results of this study are encouraging, the research entails several important limitations. In addition to the more obvious limitations pertaining to the number, age, and skill levels of the students who participated, the curriculum area involved, and the relatively short duration of the study, no data were obtained concerning the degree to which improvements in academic performance might be maintained over time. In this study, students were given quizzes over the day's material immediately at the conclusions of the lesson. A major objective of future research examining the effectiveness of response cards should be to determine whether their use produces higher scores on quizzes and cumulative tests administered at a later date.

\section{REFERENCES}

Balajthy, E. (1984). Computer simulations and reading. The Reading Teacher, 37, 590-593.

Cooke, N. L., Heron, T. E., \& Heward, W. L. (1983). Implementing classwide peer tutoring programs in the primary grades. Columbus, $\mathrm{OH}$ : Special Press.

Delquadri, J., Greenwood, C. R., Whorton, D., Carta, J. J., \& Hall, R. V. (1986). Classwide peer tutoring. Exceptional Children, 52, 573-581.

Dewey, J. (1916). Democracy and education. New York: Macmillan.

Fisher, C. W., \& Berliner, D. C. (Eds.). (1985). Perspectives on instructional time. New York: Longman.

Greenwood, C. R., Delquadri, J. C., \& Hall, R. V. (1984). Opportunity to respond and student academic achievement. In W. L. Heward, T. E. Heron, D. S. Hill, \& J. Trap-Porter (Eds.), Focus on behavior analysis in education (pp. 58-88). Columbus, $\mathrm{OH}$ : Merrill.
Hall, R. V., Delquadri, J., Greenwood, C. R., \& Thurston, L. (1982). The importance of opportunity to respond in children's academic success. In B. E. Edgar, N. G. Haring, J. R. Jenkins, \& C. G. Pious (Eds.), Mentally handicapped children: Education and training (pp. 107-140). Baltimore, MD: University Park Press.

Heward, W. L., Courson, F. H., \& Narayan, J. S. (1989). Using choral responding to increase active student response during group instruction. Teaching Exceptional Children, 21(3), 72-75.

Kline, C. S. (1986). Effects of guided notes on academic achievement of learning disabled bigh school students. Unpublished master's thesis, The Ohio State University, Columbus.

Kosiewicz, M. M., Hallahan, D. P., Lloyd, J., \& Graves, A. W. (1982). Effects of self-instruction and self-correction procedures on handwriting performance. Learming Disability Quarterly, 5, 71-78.

Lovitt, T. (1984). Tactics for teaching. Columbus, $\mathrm{OH}$ : Merrill.

Lovitt, T., Rudsit, J., Jenkins, J., Pious, C., \& Benedetti, D. (1985). Two methods of adapting science material for learning disabled and regular seventh graders. Learning Disabilities Quarterly, 8, 275-285.

Sindelar, P. T., Bursuck, W. D., \& Halle, J. W. (1986). The effects of two variations of teacher questioning on student performance. Education and Treatment of Children, 9, 56-66.

Stallard, C. K. (1982). Computers and education for exceptional children: Emerging applications. Exceptional Children, 49(2), 102-104.

Van Houten, R., Morrison, E., Jarvis, R., \& McDonald, M. (1974). The effects of explicit timing and feedback on compositional response rate in elementary school children. Journal of Applied Behavior Analysis, 7, 547-555.

Van Houten, R., \& Thompson, C. (1976). The effects of explicit timing on math performance. Journal of Applied Behavior Analysis, 9, 227-230.

Yang, F. M. (1988). Effects of guided lecture notes on sixth graders' scores on daily science quizzes. Unpublished master's thesis, The Ohio State University, Columbus.

Received October 5, 1989

Initial editorial decision March 13, 1990

Revision received May 8, 1990

Final acceptance August 8, 1990

Action Editor, Susan A. Fowler 